\title{
CASOS E HISTÓRIAS DA PROFISSIONALIZAÇÃO DOCENTE NO INSTITUTO DE EDUCAÇÃO DO DISTRITO FEDERAL (1928-1935)
}

André Luiz Paulilo ${ }^{1}$

\section{RESUMO}

O artigo trata de casos e histórias da atividade docente na capital do Brasil, a partir das discussões em torno da criação do Instituto de Educação importando interrogar a organização da carreira do magistério entre 1928 e 1935. O estudo sugere que os percalços e armadilhas da formação docente pretendida e do recrutamento dos quadros da educação foram vestígios da resistência contra as políticas de reforma da educação pública propostas por Fernando de Azevedo e Anísio Teixeira.

Palavras-chave: professores, formação, profissão docente, políticas de educação.

${ }^{1}$ Universidade Estadual de Campinas (Unicamp), Campinas/SP, Brasil. 


\title{
CASOS E HISTORIAS DE LA PROFESIONALIZACIÓN DOCENTE EN EL INSTITUTO DE EDUCACIÓN DE LA CAPITAL DE BRASIL (1928-1935)
}

\section{RESUMEN}

El artículo trata de casos e historias de la actividad docente en capital de Brasil, basado en discusiones sobre la creación del Instituto de Educación y cuestionando la organización de la carrera docente entre 1928 y 1935. El estudio sugiere que los percances y trampas de la formación docente pretendida y del reclutamiento de los cuadros de la educación fueron vestigios de la resistencia contra las políticas de reforma de la educación pública propuestas por Fernando de Azevedo y Anísio Teixeira.

Palabras clave: profesores, formación, profesión docente, políticas de educación.

\section{CASES AND HISTORIES OF TEACHING PROFESSIONALISATION IN EDUCATION INSTITUTE FROM CAPITAL OF BRAZIL (1928-1935)}

\begin{abstract}
This paper investigates teaching cases and histories in capital of Brazil, based on discussions about the creation of the Institute of Education, and questioning the organization of the teaching career between 1928 and 1935. The study suggests that the setbacks and arrangement of the intended teacher formation and recruitment of education staff were remnant of resistance against education reform policies proposed by Fernando de Azevedo and Anísio Teixeira.
\end{abstract}

Keywords: teachers, formation, teaching profession, education policies.

\section{CAS ET HISTOIRES DE LA}

\section{PROFESSIONNALISATION D'ENSEIGNANTS DANS} L'INSTITUT D'EDUCATION AU CAPITAL DU BRÉSIL

\section{(1928-1935)}

\section{RÉSUMÉ}

L'article traite des cas et de l'histoire de l'activité pédagogique au capitale du Brésil, à partir de discussions sur la création de l'Institut de l'éducation, interroger l'organisation de la carrière d'enseignant entre 1928 et 1935. L'étude suggère que l'incidents et pièges de la formation des enseignants et du recrutement des cadres de l'enseignement étaient des traces de résistance aux politiques de réforme de l'enseignement public proposées par Fernando de Azevedo et Anísio Teixeira.

Mots-clés: enseignants, formation, profession enseignante, politiques d'éducation. 


\section{INTRODUÇÃO}

Sob a designação de técnico em escolarização, Jorge Nagle (1974, p. 101102) identificou uma nova categoria profissional, aquela que iria tratar, com quase exclusividade, dos assuntos educacionais. Na sua interpretação, os assuntos educacionais só constituíram um espaço de profissionalização no Brasil a partir da década final da Primeira República, quando analisados pelos "técnicos", os problemas da escolarização se comprimiram num domínio especializado. Para o mesmo autor, a profissionalização na educação se deu menosprezando as vinculações desses problemas com os de outra ordem.

Esta tese de Nagle não é ponto pacífico na historiografia da educação. Marta Carvalho (1998) questiona a ideia de uma crescente dissociação entre problemas sociais, políticos e econômicos e problemas pedagógicos com a emergência dos profissionais da educação no movimento de renovação escolar de fins dos anos 1920. Suas pesquisas sobre a Associação Brasileira de Educação (ABE) sugerem outro enfoque para a relação "educação e política" no período ao perceber na pressão pela abertura de espaço nos governos estaduais para esse grupo de "técnicos" ou de "profissionais da educação" uma politização em outros termos. Por outro lado, os estudos sobre a atuação docente nos oitocentos brasileiro advertem que os modos pelo quais a educação constituiuse num domínio de atividade especializada não é privilégio do século XX. As teses de doutoramento de Inára de Almeida Garcia Pinto (2011) e Angélica Borges (2014), por exemplo, investigam sujeitos que exerceram a docência durante toda uma vida, participando de diversas das suas instâncias e instituições e contribuindo para pensá-las.

Além da relação com um domínio especializado de atuação, há outros aspectos relevantes para se considerar quando se pretende estudar a história da profissionalização docente. Nóvoa (1986, 1991 e 1992) contribuiu para esclarecer o papel de outros três deles. Primeiro, o enquadramento estatal dos processos de seleção e recrutamento de professores criou as condições de profissionalização do magistério. Nesse sentido, a formação docente passou a 
ocupar um lugar privilegiado de configuração da profissão docente por meio da criação de instituições estatais para a produção de um saber socialmente legitimado relativo às questões de ensino. Mesmo sob a tutela estatal e de seus mecanismos de controle, a atuação na profissão docente afirma um espaço de autonomia que se consolida com o incremento do associativismo. A Nóvoa parece que, uma vez combinados, o enquadramento estatal, a formação para a docência e o associativismo docente explicam as forças que faz o exercício do magistério oscilar entre a funcionarização e uma profissionalização mais autônoma.

Ainda que controvertida, a história da profissão docente foi objeto de uma síntese de Vicentini e Lugli (2009) muito útil à tarefa de compreensão dos processos mais conjunturais de afirmação de práticas e de valores característicos da atuação no magistério hoje. Seguindo de perto Nóvoa, mostram que no Brasil o enquadramento estatal ocorre desde a Colônia, com as reformas pombalinas mas que, no entanto, só implementará cursos de formação oficiais a partir de meados da década de 1880: 1835 nas Províncias do Rio de Janeiro e de Minas Gerais e, 1836, na Bahia. Em São Paulo, a Escola Normal foi organizada em 1846. A identificação dos esforços para a formação do magistério de então até 1980 é central na discussão que Vicentini e Lugli fazem do processo de profissionalização do professorado, pois mostram ser por meio das instituições de preparo para a docência que o poder público controla a autorização de exercício e produz a legitimidade social do magistério.

Outro aspecto nuclear da estruturação do espaço profissional do magistério presente nas análises de Nóvoa e estudado por Vicentini e Lugli no Brasil foi a movimentação dos professores na defesa de seus interesses, o associativismo. Apesar das lacunas que identificam na produção sobre o movimento de organização dos professores no Brasil, mostram uma tradição secular de articulação, reivindicação e participação política. Não se trata, entretanto, de processos homogêneos de estruturação ou legitimação de entidades representativas. Ao contrário, sobressaem as particularidades da 
história de mobilização docente, resultado da heterogeneidade da categoria e da abrangência regional das suas associações e entidades sindicais. Em todo caso, trata-se de um processo suficientemente sistemático para que Vicentini e Lugli pudessem analisá-lo como estratégia de representação profissional do magistério. Mesmo reforçando as análises desenvolvidas por Nóvoa, esse empreendimento de síntese incorpora pautas muito próprias do debate atual acerca do magistério como categoria profissional. Assim, as condições de exercício do magistério e as representações sociais da docência são problematizadas por Vicentini e Lugli de modo a lembrar-nos da multiplicidade de dimensões que tem a discussão sobre a profissão docente e seu significado na sociedade contemporânea.

O esforço para compreender a história da profissão docente reúne ainda outros estudos importantes. Conforme lembra Catani (2000), contribuíram para esse tema Arroyo (1985), Kreutz (1985) e Nadai (1991). Mais recentemente, Libânea Xavier (2013) soma ao conjunto apontado por Catani uma análise elucidativa da construção da profissão docente e da sua historiografia. A sua atenção aos estudos de Lemos (2011), Mendonça e Cardozo (2002), Mendonça e Xavier (2008) e Schueller (2002) mostram a afirmação do tema nestas primeiras décadas do século XXI.

A nenhuma dessas formas de abordar o tema falta a sugestão de que o recrutamento, a formação e o exercício docente configuraram as relações através das quais o profissionalismo docente se afirmou. Nesse sentido, mesmo sem outra metodologia que não a proposta por Nóvoa para interrogar a profissionalização docente, o escopo deste artigo é tratar de dois episódios específicos ocorridos entre 1928 e 1935 na cidade do Rio de Janeiro, então capital do país. À maneira de um estudo de caso, busquei compreender o modo como na transformação da Escola Normal do Distrito Federal em Instituto de Educação seus responsáveis fizeram da carreira outro espaço de ingresso e atuação docente.

A principal questão analisada é a ambiguidade das formas de 
recrutamento docente quando da criação do Instituto de Educação do Distrito Federal. De modo que, primeiro, procurou-se discutir o preparo para a docência como forma de enquadramento estatal. E, assim, pretendeu associar a reorganização do curso de formação de professores do Instituto de Educação ao processo de reestruturação da carreira docente deflagrado em 1932. Depois, procurou-se analisar alguns casos que permitem explorar algo dos limites da tutela estatal e dos mecanismos de controle do professorado, tendo em vista dar alguma dimensão à sua precariedade.

\section{TEMPOS DE FORMAÇÃO, ESPAÇOS DE ATUAÇÃO DOCENTE NA CAPITAL DO BRASIL NOS ANOS 1930}

Em 1927, Fernando de Azevedo tomou providências para a construção de um novo edifício para a Escola Normal do Distrito Federal, por entender que era preciso providenciar instalações condignas à instituição destinada à formação propedêutica e profissional dos professores. Na forma como Azevedo (1929, p. 82) apresentou à imprensa o projeto de construção:

O edifício será, só por si, uma forte, luminosa lição de higiene e de civismo. As suas linhas esculturais, brasileiras, digamos assim, ensinam o gosto das nossas coisas, a inteligência e o bem querer do país, pelo cultivo das nossas tradições mais belas e significativas. As salas amplas, harmoniosas, lavadas de luz, incutem, de par com a ideia de limpeza, a de alegria tropical e sadia força de nossa natureza. Essas impressões persistentes dominam o interior, onde as evocações da nossa natureza, dos nossos costumes e dos nossos fatos cívicos constituirão uma constante sugestão de nacionalidade.

O novo prédio então construído na rua Mariz e Barros foi estruturado para organizar o espaço de preparação para o magistério num ambiente educativo. Em estilo tradicional brasileiro, sua arquitetura conferia expressão material à política de educação dirigida por Fernando de Azevedo. 
Figura 1 - Vista área da Escola Normal.

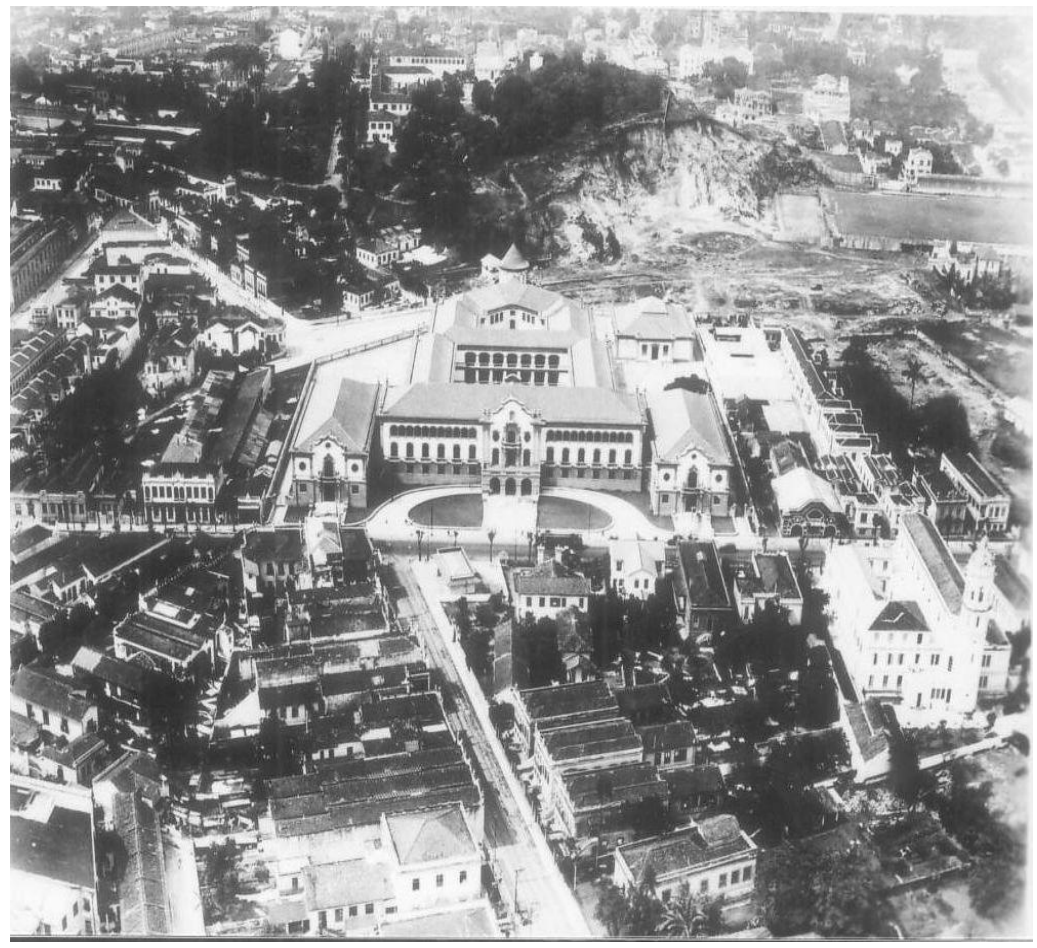

Fonte: Fotografia de S. H. Holland, 4 out. 1930, (IEB/USP) - em Abdala (2003).

Mais que monumental, a construção pretendia integrar o padrão arquitetônico tradicional e os princípios da Escola Nova. Além de possuir salas de aula bem iluminadas e ventiladas, acomodava laboratórios de física e química, biblioteca e espaços para a prática de ensino - Escola de Aplicação e Jardim da Infância. Tratava-se de um prédio concebido para abrigar cinco anos de curso. Os três iniciais, de caráter propedêutico, previam a formação por meio de uma cultura geral sólida. Os dois últimos anos eram de natureza profissional e visavam subsidiar a prática com um repertório de conhecimentos especializados capaz de fundamentar o exercício da docência. Para Azevedo (1930, p. 484), o Curso Normal deveria articular "demonstração, experimentação e prática do ensino". Vidal (1998, p. 90) já mostrou bem que esse propósito motivou as ações de reforma das condições de preparo para o magistério entre 1928 e 1930 na capital do país.

Fernando de Azevedo não inaugurou o edifício que fez construir. Os 
acontecimentos políticos de 1930 precipitaram o fim da sua administração na Diretoria Geral de Instrução Pública do Distrito Federal. O novo prédio foi ocupado sem solenidade e às pressas, para evitar o aquartelamento das tropas vindas do sul. Conforme depoimento de Marília Marques da Costa (apud Lopes, 2006, p. 66-67):

O prédio novo já estava pronto em 1930, ano em que iniciei meus estudos. A diretoria foi avisada que os soldados vinham do Rio Grande do Sul e se instalariam em qualquer prédio público que estivesse vazio. E o Instituto era um prédio público que ainda não tinha sido inaugurado. O secretário Antônio Vitor passou dias e noites lá. Primeiro levaram o material dos arquivos, depois cadeiras e mesas. Todo mundo ajudava e foi feita a mudança, em menos de uma semana.

O rearranjo que se seguiu ao advento revolucionário de então conduziu, em outubro de 1931, Anísio Teixeira ao cargo que foi de Azevedo e o fim dos inquéritos, apurações e perseguições à sua obra e aos seus colaboradores pelos opositores da última reforma. A partir daí o preparo para a docência mudou consideravelmente na capital do país. Por um lado, a transformação em Instituto de Educação da antiga Escola Normal e a nova regulamentação de preparo técnico de professores primários, secundários e especializados alterou os ciclos de formação e os seus programas de curso. Por outro, a reforma na estruturação da Diretoria Geral de Instrução Pública do Distrito Federal e na organização dos quadros do magistério alterou as possibilidades de ascensão horizontal na função docente e criou condições para fazer da carreira um meio de promoção vertical, através da nomeação para funções e cargos técnicos.

Em 1932, o primeiro passo foi dar outra organização à Diretoria Geral de Instrução Pública e criar o quadro de professores adjuntos de $4^{\mathrm{a}}$ classe do ensino primário. $\mathrm{O}$ decreto $\mathrm{n}^{\mathrm{o}} 3.763$, de $1^{\mathrm{O}}$ de fevereiro, modificou algumas disposições do Código de Ensino de 1928 para criar serviços técnicos e administrativos de centralização e modificar os quadros do magistério. 
Por um lado, Anísio Teixeira transformou a Diretoria Geral de Instrução Pública criando 13 serviços técnicos e administrativos:

1. Matrícula e frequência escolares; 2. Classificação e promoção de alunos; 3. Programas escolares; 4. Obras sociais escolares, Peri escolares e pós-escolares; 5 . Educação de saúde e higiene escolar; 6 . Educação física; 7. Música e canto orfeônico; 8. Ensino secundário geral e profissional; 9. Prédios e aparelhamentos escolares; 10. Estatística e cadastro; 11. Expediente e publicidade administrativa; 12. Pessoal e arquivo; 13. Contabilidade. (DISTRITO FEDERAL, 1932a, p. 359)

Desse modo, as antigas subdiretorias técnica e administrativa deram lugar a um arranjo diversificado de funções especializadas. Conforme reconheceu Anísio Teixeira (1935, p. 58), esse reajustamento visava dar um melhor encadeamento aos diferentes serviços do sistema escolar e prover de atenção sistematizada as necessidades do ensino.

Por outro lado, Anísio Teixeira criou o quadro de professores-adjuntos de quarta classe do ensino primário, cujo número fixou em 500. Até então os quadros do magistério se organizavam em professores e professores-adjuntos até a terceira classe. A medida disciplinou o ingresso no magistério carioca provendo-lhe as seguintes condições:

1. diploma de curso normal; 2. estágio de dois anos no magistério municipal como substituto efetivo ou estagiário, ou aprovação em curso de aperfeiçoamento de professores organizados pela Diretoria Geral de Instrução, na Escola Normal; 3. aptidão pedagógica apurada no estágio ou em curso de aperfeiçoamento organizado na Escola Normal pela Diretoria Geral de Instrução. (DISTRITO FEDERAL, 1932a, p. 361).

Depois de condicionar assim o ingresso nos quadros do magistério, um segundo passo foi dado no sentido de alterar a preparação para o exercício da docência nas escolas da capital federal. Por meio do decreto $\mathrm{n}^{0} 3.810$, de 19 de 
março do mesmo ano, Anísio Teixeira transformou em Instituto de Educação a antiga Escola Normal do Distrito Federal. Criou, então, a Escola Secundária e a Escola de Professores. Tanto organizou em dois ciclos, um fundamental de cinco anos e outro complementar de três anos, o curso da Escola Secundária e distribuiu em até quatro anos os cursos de formação da Escola de Professores quanto vinculou à conclusão do Secundário o ingresso na Escola de Professores. Efetivamente, com esse expediente, Anísio Teixeira faz do preparo para o magistério um curso de nível superior e aumenta em três anos a formação necessária para a diplomação na Escola de Professores.

Nova movimentação acerca do arranjo dos quadros do magistério do Distrito Federal se dá em dezembro de 1932. Dez meses depois da criação do quadro de professor-adjunto de quarta classe, Anísio Teixeira (1935, p. 190) submete e vê aprovado pelo governo o projeto de lei que unificava as classes do magistério primário com uma justificativa na qual observava:

\footnotetext{
Com efeito, numa classe em que o número de vagas a preencher é sempre inferior ao de elementos eficientes com direito ao acesso, a preferência dada a um determinado grupo, melhorando-lhe as condições de vida, implica numa tão flagrante injustiça para com os demais, colocados, pelo próprio mérito, em igualdade de condições com os contemplados, que não se lhes pode negar, quando não o direito, ao menos razões de atribuir a causas menos lisas a decepção de que foram vítimas.

Tudo isto gera no seio da coletividade um espírito de competição pessoal, em cuja névoa se obliteram as visões, enxergando nas vitórias mais belas simples consequências de favores granjeados fora do campo em que se agitam os valores funcionais. E são bem fáceis de avaliar os males que decorrem de um tal estado de ensino.
}

O decreto $\mathrm{n}^{\mathrm{O}} 4.088$ estabelece regras e condições para aumentos progressivos de vencimentos combinando tempo de experiência e aperfeiçoamento técnico. Prevê a concessão de aumentos bianuais regulares ou anuais transitórios e estabelece os casos de impedimento: 
1. Não tiver servido durante um ano de efetivo exercício em zona rural ou suburbana remota; 2. Houver incorrido em qualquer das penalidades previstas nas leis do ensino; 3. Tiver dado mais de 30 faltas anuais, justificadas ou não; 4. Tiver gozado licença por mais de três meses; 5 . Afastar-se do exercício da classe para aceitar comissões estranhas aos serviços escolares do Distrito Federal; 6. Tiver recusado sem causa justificada, a juízo dos chefes de serviço, comissões que lhe forem atribuídas na escola e serviços extraordinários inerentes às suas funções, determinados pelo Diretor Geral; 7. Tiver revelado pouca eficiência na direção da classe ou no serviço especial para que estiver designado, verificada pelos chefes de serviço; 8. Tiver oferecido dificuldade às iniciativas técnicas e administrativas da Diretoria Geral, por negligência ou má vontade; 9. Não tiver frequentado com proveito os cursos de aperfeiçoamento que lhe tiverem sido determinados pela Diretoria Geral, de acordo com as funções que estiver exercendo. (DISTRITO FEDERAL, 1932b, p. 415)

Esse sistema de exigências para obtenção dos aumentos anuais é que Anísio Teixeira apresenta como carreira profissional. Para o professorado primário a tabela de vencimentos estipulava como vencimento anual inicial a quantia de 4:200\$000 e aumentos bienais de 600\$000, podendo-se até chegar ao máximo de 12:000\$ooo anuais. A lógica da promoção do magistério foi de fato alterada no sentido proposto por Anísio Teixeira (1935, p. 191), que via na lei de unificação um estímulo ao espírito de cooperação e ao constante aperfeiçoamento:

\footnotetext{
Desaparecida a luta por merecimento, jungida no sistema antigo à competição individual entre os professore, criaram-se novas condições de cooperação e trabalho em comum.

O espírito de cooperação encontrou novos estímulos para se desenvolver, uma vez que ninguém podia com o seu próprio mérito prejudicar o colega, só havendo, assim, motivos para se trabalhar num espírito de associação, camaradagem e mútuo auxílio.
}

No entanto, ao completar a reforma da Diretoria Geral de Instrução Pública, organizando em Departamento de Educação a administração central do ensino no ano de 1933, Anísio Teixeira hierarquiza o prestígio profissional nos serviços da educação de outro modo. Mesmo que ainda conferindo autoridade 
por meio da nomeação e da designação para o trabalho comissionado, com a criação do Instituto de Pesquisas Educacionais, 5 divisões e mais de uma dezena de seções, ampliam-se as especialidades técnicas. Por meio do decreto $\mathrm{n}^{0} 4.387$, de setembro de 1933 foram criados:

1. O Instituto de Pesquisas Educacionais, com um diretor, também chefe da Divisão de Pesquisas Educacionais e 6 chefes de seção; 2. A Divisão de Bibliotecas, Museus e Rádio-difusão, com um chefe de divisão e dois chefes de seção; 3. A Divisão de Obrigatoriedade Escolar e Estatística, com 1 chefe de divisão e 2 chefes de seção; 4. A Superintendência de Educação Elementar, com 14 superintendentes e 60 orientadores especializados; 5. A Superintendência de Educação Secundária Geral e Técnica e de Ensino Extensão, com um superintendente com auxiliares do quadro do Departamento que fossem necessários; 6. A Superintendência de Educação de Saúde e Higiene Escolar, com professores de saúde em número necessário; 7. A Superintendência de Educação Física, Recreação e Jogos, com auxiliares imediatos que se tornassem necessários; 8. A Superintendência de Ensino Particular, com 14 superintendentes e 30 orientadores de ensino. (DISTRITO FEDERAL, 1933, p. 428-429)

Mesmo os cargos de direção e chefia de seção e a superintendência de Desenho e Artes Aplicadas, sendo funções exclusivas de docentes efetivos da Escola de Professores, a rede de auxílio e atribuições criadas em torno dos novos serviços do Departamento amparou gratificações, alocação de professores e oportunidades de especialização ainda inéditas no ensino público. Não parece fora de propósito sugerir que essa outra organização funcional interferiu nas formas de conferir prestígio e autoridade profissional ao magistério primário. A tendência de entender a expansão dos quadros técnicos da educação na perspectiva da mera burocratização da administração central, no entanto, apenas simplifica a interpretação. A ideia que, por exemplo, Raquel Gandini (1980, p. 130) fez da "assessoria técnica" criada por Anísio Teixeira reduz a questão ao tema do conservadorismo legalístico-burocrático: aumento do quadro burocrático, aumento do grau de burocratização e, principalmente, aumento do grau de controle sobre os professores. Também a análise que Clarice Nunes (2000, p. 238) faz dessa rede de serviços, cargos e funções 
privilegia a consciência racionalizadora, o esforço ideologizador e o empenho da administração central do ensino para moldar uma expectativa de futuro à população da capital em detrimento das oportunidades de ascensão profissional então abertas na educação pública.

Mesmo assim, não escapou à percepção de Gandini e Nunes que os postos então criados redefiniram o exercício da educação enquanto profissão. Entretanto, o que para uma delas se passa como restrição e controle dos professores e da população, para a outra se trata de uma estratégia de ampliação do exercício do poder por parte dos educadores profissionais para além do "fechado território político-partidário" (NUNES, 2000, p. 589). Infelizmente, além da reputação de alguns dos quadros dos serviços escolares organizados entre 1932 e 1933, pouco se conhece hoje das formas como à época a administração pública redefiniu o status profissional na educação. Penso que mais que de um escalonamento pertinente de vencimentos, a carreira docente foi feita de "oportunidades" no interior do aparelhamento do seu controle. Entre os anos 1920 e 1930 o reenquadramento realizado por Anísio Teixeira conservou posições, mantendo os nomes-chave da reforma anterior nas direções, chefias e superintendências então criadas. Assim, por um lado, Arteobela Frederico, Celina Padilha, Felicidade de Moura Castro, Maria do Carmo Vidigal, Laudimila Trotta, Paulo Maranhão e Zélia Braune atuaram como superintendentes do ensino primário e Paschoal Lemme e Joaquim Faria Góes como superintendentes da educação secundária geral e técnica e do serviço de extensão consolidando-se como autoridades técnicas do ensino. Por outro, Delgado de Carvalho na direção do Instituto de Pesquisas Educacionais com Roquete Pinto na seção de museus e radiodifusão, Pedro Matos na Divisão de Obrigatoriedade Escolar e Estatística, Nereu Sampaio na de Prédios e Aparelhamentos Escolares e Arthur Ramos na secção de Ortofrenia e Higiene Mental ou de Heitor Villa Lobos na superintendência da educação musical e artística emprestaram o seu prestígio como intelectuais e professores reputados aos serviços que comandariam. 
A esses exemplos escapa um ainda desconhecido, mas importante conjunto de docentes que a partir das designações do Departamento de Educação atuariam em comissão como orientadores especializados, professores de saúde e auxiliares de seção. Como nos escalões mais altos da administração, também nesse nível não convém ignorar que a carreira docente significou mais que um escalonamento de vencimentos, outro espaço de atuação profissional.

\section{UMA PROFISSÃO AOS "TRANCOS E BARRANCOS": CASOS DE PERCURSO E DE FORMAÇÃO DOCENTE}

O cuidado nas manobras e o zelo com que Anísio Teixeira, entre 1933 e 1934, administrou as alterações no Instituto e no Departamento de Educação e a unificação dos quadros do magistério não evitaram os flagrantes de conciliação política e favorecimento.

O primeiro deles foi testemunhado por um colaborador próximo. Entre 1931 e 1935, Paschoal Lemme secretariou Anísio Teixeira no Departamento de Educação. Desse período, Paschoal Lemme (1988, p. 150-151) retém na memória uma das nomeações em especial. Para cuidar das propostas dos estabelecimentos particulares de ensino para receberem crianças pobres mediante contratos com o Departamento de Educação criou-se primeiro um serviço de assistência aos menores, mais tarde, uma superintendência especializada para o mesmo propósito. Pareceu a Paschoal Lemme que a candidata de Anísio Teixeira para dirigir o novo serviço era a professora Maria Loreto Machado. Tratava-se de mestra das mais competentes considerando sua projeção na carreira. Fora uma das primeiras mulheres nomeadas para o cargo de inspetora de ensino já na administração anterior e à época atuava como superintendente de ensino primário. No episódio de que trata Paschoal Lemme, já atuavam juntos na comissão responsável para indicar quais propostas deveriam ter a preferência para receber as crianças em questão. Entretanto, 
"sobreveio um incidente que diz bem do ambiente em que ainda se vivia naqueles primeiros tempos agitados da revolução vitoriosa". Paschoal Lemme (1988, p. 151) narrou assim o episódio:

Para a Câmara Municipal de Vereadores tinha sido eleito pelo Partido Autonomista, fundado por Pedro Ernesto, um oficial do exército, que iniciava então a sua carreira política e que se consagrou como a mais longa de um parlamentar brasileiro - o intendente Frederico Trotta. Certo dia, vio-o entrar no gabinete do diretor do Departamento de Educação, numa atitude muito agressiva. Temi que o pior pudesse acontecer, mas, felizmente, tudo acabou se acomodando. Frederico Trotta pleiteava para a sua esposa, a professora Ludímia Trotta a nomeação para o cargo de superintendente da assistência a menores. D. Ludímia era uma diretora de escola primária de muitos méritos. Acabou por conseguir a desejada nomeação, desempenhando o cargo, muitos anos, com toda a eficiência e dedicação.

É especialmente significativo o fato de Frederico Trotta não "cavar" 2 para sua esposa um reenquadramento de vencimentos, uma promoção na carreira, como a entendia Anísio, mas outro cargo. Diretora de escola primária de muitos méritos, Laudímia Trotta foi nomeada para dirigir uma nova superintendência, galgando prestígio no interior do quadro técnico criado pela reforma de 1932/33. O pragmatismo do intendente deixa ver com alguma nitidez que as oportunidades de ascensão nos quadros do magistério já escapavam da escola e da sua inspeção para alcançar as funções técnicas e especializadas da burocracia educacional.

Outro caso significativo de "cavação" é o lembrado por Genolino Amado, em livro de crônicas chamado O Reino Perdido, publicado em 1971, e que conheci por meio da leitura de um texto de Itamar Freitas (2006, p. 249) sobre o recrutamento de professores para o magistério secundário. $\mathrm{O}$ encontro

\footnotetext{
2 Expressão utilizada à época como sinônimo de emprego obtido por proteção. No seu sentido dicionarizado a palavra significa arranjo, vantagem, negócio obtido por proteção. (Cf. Dicio: Dicionário Online de Português. Disponível em: https://www.dicio.com.br. Acesso em Ago. 2018).
} 
de Genolino com Anísio Teixeira, seu ex-colega da Faculdade de Direito da Bahia, se deu na Rua do Ouvidor no Rio de Janeiro e foi relembrado do seguinte modo em O Reino Perdido:

- Olá! Então, perdeu a fé? [Na Bahia, Anísio queria abandonar o curso de Direito para ingressar na ordem dos Jesuítas).

- Sim. E você?

-Perdi a descrença.

Rimos, ele com o seu raro, esplêndido sorriso. Perguntou-me de minha vida. Contei-lhe:

- Estou aqui de passagem. Mas, pensando em vir morar no Rio.

-E por que não vem?

- Não posso vir de mãos abanando. Preciso de uma base qualquer, mesmo pequena.

- Bem, isso eu resolvo. Quer ser professor secundário da Prefeitura?

-Professor? Não tenho prática, nunca ensinei.

- Melhor. Os experientes não me convêm. Lecionam de maneira antiquada e resistem à modernização dos métodos. Resolvi escolher gente nova, capaz de se ajustar a uma nova didática. Estou aproveitando pessoal do nosso tempo na Bahia. O Sodré Viana, o Álvaro Barbosa Sobrinho. Também nunca ensinaram. Se você quiser, nomeio.

- Homem ... nomeia mesmo?

- Duvida por que? (...)

-Pois, se puder nomear...

- Demora só uns três ou quatro dias. Acompanhe nos jornais a seção da Prefeitura e me apareça quando o ato sair. (AMADO, 1971, p. 14 apud FREITAS, 2006, p. 249).

O desdobramento desse encontro foi sintetizado pelo próprio Itamar Freitas (2006, p. 249-250), que faz humor com o caso nos seguintes termos:

E a nomeação saiu mesmo, algumas semanas depois. Só havia um problema. Genolino teria que dar aulas de inglês, idioma que decorara apenas alguns rudimentos nos cursos particulares e de preparatórios. O suficiente para "aprender a passar" nos exames parcelados do 
Ginásio da Bahia. Nas semanas que se seguiram à oficialização no emprego, o publicista esforçou-se bastante com as gramáticas e enfrentou a tarefa na Escola Paulo de Frontin. Tempos de reformas, como anunciou Anísio, Genolino esbarrou nas instruções programáticas: "método direto, o mínimo de teoria, puxar conversa em inglês para começo de conversa". Muito diferente da metodologia empregada pelo professor de inglês do Ateneu Sergipense e dos mestres de francês e inglês com os quais convivera em Salvador na década de 1910. Pensou em desistir, mas - homem de sorte esse Genolino! - acabou requisitado por Roquette Pinto para trabalhar na PRD-5, emissora educativa da Prefeitura do Distrito Federal. E por lá ficou uma década, escrevendo pequenos ensaios, sem horário e sem o rígido controle do ponto. A vida que pediu a Deus.

A se acreditar em Freitas (2006), uma característica de funções como as de Genolino Amado na Rádio Escola Municipal (PRD-5) era permitir escapar ao rígido controle do ponto e trabalhar sem horário. E se o episódio diz muito sobre o modo como a "modernização dos métodos" amparou uma política de pessoal pouco tolerante com a experiência docente, é igualmente indicativo das soluções de compadrio que então se adotou. Conforme considerou Paschoal Lemme (1988, p. 151), "ou porque se criara em um ambiente de política de província em que imperava [...] a troca de favores como ingredientes normais das relações entre as pessoas e entre essas e as autoridades", ou porque "entendesse as manifestações de ambições ou interesses pessoais como pecados menores, que não deveriam prejudicar a consecução dos objetivos mais altos em que estava empenhado", Anísio Teixeira manobrou em terreno bastante acidentado.

Na contramão das cavações do tipo descrito por Paschoal Lemme e Genolino Amado, as exigências para admissão à Escola de Professores do Instituto de Educação observavam critérios rigorosos. Vinculado à conclusão do Secundário o ingresso na Escola de Professores desde 1933, o decreto 5.00o, de 11 de julho de 1934, regulamentaria a admissão à Escola Secundária limitando ao primeiro ano do curso fundamental a entrada nesta escola e, assim, vedando a aceitação de alunas por transferência e restringindo a 10\% as vagas para candidatos masculinos. Isso significava submeter a candidata a exames médicos 


\section{e provas escritas, orais e gráfica de desenho. Conforme determinava o decreto $\mathrm{n}^{\mathrm{0}}$ 5.000, em seus artigos de 54 a 58 :}

Art. 54 - A admissão só poderá ser feita na primeira série do ciclo fundamental, sendo vedada a aceitação de alunos por transferência de qualquer outro estabelecimento de ensino.

Art. 55 - A inscrição se processará de 1 a 15 de fevereiro mediante requerimento dirigido ao diretor da Escola, entregue até o dia 10 do referido mês, dele constando a idade, a filiação, a naturalidade e a residência do candidato.

Parágrafo único - $\mathrm{O}$ requerimento, pedindo inscrição nos termos deste decreto, virá acompanhado dos seguintes comprovantes:

a) atestado de vacinação antivariólica recente, com a firma devidamente reconhecida;

b) certidão original de registro civil;

c) recibo do pagamento da taxa de inscrição;

d) duas fotos do candidato.

Art. 56 - À medida que a inscrição se processe os candidatos irão sendo submetidos a exame de saúde, mediante guia que lhes será fornecida pela Secretaria do Instituto.

$\S 1^{0}$ - No exame de saúde, que é de caráter eliminatório, serão recusados os candidatos que sofrerem de doenças transmissíveis, ou apresentarem defeitos que tornem inconveniente seu convívio com os outros alunos, ou que os inabilitem para o exercício do magistério.

$\S 2^{\mathrm{O}}$ - Poderão ser aceitos, entretanto, os candidatos cujas condições de saúde possam vir a normalizar-se mediante tratamento adequado, que será, então, exigido, obrigando-se os candidatos em tal situação a nova inspeção um ano depois.

Art. 57 - Os candidatos aceitos após o exame de saúde serão submetidos a testes mentais, com caráter também eliminatório, para aproveitamento dos que apresentarem melhores quocientes de inteligência.

Art. 58 - Os candidatos aceitos submeter-se-ão às seguintes provas, sendo que para as mencionadas nas letras a e b vigorarão os programas correspondentes ao Colégio Pedro II:

a) escritas de português e aritmética, cada uma das quais com caráter eliminatório;

b) orais de português, aritmética, geografia, história do Brasil e ciências naturais;

c) gráfica de desenho, a mão livre (cópia do natural). 
$\S 1^{0}$ - A prova escrita de português, na qual também será apreciada a caligrafia, constará de duas partes, ditado e redação.

$\S 2^{0}$ - A prova escrita de aritmética constará de problemas e exercícios apresentados sob a forma de testes.

$\S 3^{0}$ - As provas orais constarão de arguição sobre pontos sorteados dentre os dos programas.

$\S 4^{0}$ - As provas eliminatórias só habilitam a prosseguir nos exames os candidatos que, em cada uma delas, obtiver a nota mínima de cinquenta. (DISTRITO FEDERAL, 1934, p. 486-487).

Foi importante a discussão em torno dos critérios de admissão ao magistério no Instituto de Educação do Distrito Federal. Carlos Sá (1933), Mário de Brito (1934) e Lourenço Filho (1934) valeram-se do "Boletim de Educação Pública” ou dos “Arquivos do Instituto de Educação” para esclarecer quais deviam ser os requisitos de admissão em um conjunto bastante homogêneo de artigos. Liete Accácio (1993, p. 176), inclusive, conseguiu testemunhos de "ajustes de última hora" para adequar-se aos critérios de peso ideal. Há relatos de colocação de pesos em peças de lingerie e ingestão de manteiga antes do exame de saúde.

A despeito desses estratagemas, pareciam existir critérios mais obtusos e incontornáveis. Jerry Dávila, em estudo de 2003, percebeu nos exames de saúde eliminatórios uma celebração de normas eugênicas e no conjunto dos dispositivos de admissão uma fé acrítica na ciência e no profissionalismo. Suas análises apontam como resultado não a seleção da "fina flor da população", mas "um sistema escolar mais excludente em suas práticas de treinamento e contratação, e cada vez mais discriminatório em seu modo de tratar os alunos" (DÁVILA, 2006, p. 193).

Como mostrou Diana Vidal (2001, p. 109), "a concentração de discursos, defendendo os critérios de admissão e reforçando a exigência de oito anos no Instituto, no avesso, apontava para uma zona de disputa entre educadores, alunas e pais”. Na conclusão do ano letivo de 1936, pais e alunas conseguiram a aprovação do decreto $\mathrm{n}^{0} 156$, de 30 de dezembro, determinando 
a expedição de diploma de professor primário às que, conforme esclarece a mesma autora, "matriculadas na antiga Escola Normal até o ano de 1932, inclusive, já tivessem cumprido 5 anos de escolaridade com aproveitamento" (VIDAL, 2001, p. 110). Em depoimento obtido por Anna Barreto (1985, p. 114) através de entrevista com uma ex-normalista da época, no ano de 1985, tem-se o seguinte testemunho:

Em 30 ou 32, no ano em que entrei, passaram a ser cinco de ginásio, uma sexta série e dois de normal. Quando nós já estávamos na sexta série, tem sempre alguém que descobre que a lei não está sendo cumprida. Entramos sob a lei antiga, então não vamos cursar os oito anos. Aí começaram a mexer, mexer, e saíram com cinco anos de Instituto. As que saíram foram chamadas de "decretinas", por causa do decreto.

Jocosamente chamadas de "decretinas", este grupo, segundo Schaffel (1999), recusava-se a reconhecer a elevação do ensino normal ao nível superior. $\mathrm{Na}$ interpretação de Lopes (2006, p. 226), o decreto $\mathrm{n}^{0} 156$ que compendiou as leis 109 e 129, de 21 de outubro e 2 de dezembro, que extinguiu a exigência do curso complementar e superior para a formação de professores para a escola primária. Em consequência, não só um grande número de professores se diplomou sem ter contato com as matérias específicas de sua formação profissional. Um ano após a exoneração de Anísio Teixeira do Departamento de Educação do Distrito Federal, dava-se o início da desestruturação da sua obra administrativa no Instituto de Educação.

\section{CONSIDERAÇÕES FINAIS}

Para uma história da profissionalização da docência no Brasil, o estudo das estratégias de recrutamento, formação e exercício do magistério propostas quando da criação da Escola de Professores do Instituto de Educação do Rio de Janeiro é indispensável. Não só porque se tratou de insistir numa perspectiva 
meritocrática e especialmente exigente de ingresso e promoção na carreira. $\mathrm{O}$ período também foi de uma espécie de "enobrecimento excludente, seletivo e elitista do preparo docente" (PAULILO, 2017, p. 130). De fato, no início da década de 1930, a transformação da Escola Normal do Distrito Federal em Instituto de Educação do Rio de Janeiro procurou expressar a relevância social atribuída ao exercício da docência.

Entretanto e mesmo reconhecendo nessa transformação uma proposta profícua e cheia de consequências, o intuito aqui foi também sugerir que a conservação de práticas de favorecimento e privilégio e de resistência se mostrou tão indispensável à história da profissionalização da docência no Brasil quanto o esforço de mudança. Assim, a prática da "cavação" ou a recusa de parte das alunas em reconhecer as novas exigências testemunham algo dos limites do programa de reestruturação da carreira docente à época. Em meio aos arranjos e disputas próprios do período é possível perceber a ambiguidade da política de pessoal da administração central da educação, o seu viés excludente e, em alguma medida, a resistência que sofreu.

Nesse sentido, o desejo inicial de entender como o magistério se consolidou em carreira pública entre 1932 e 1935 encontrou no estudo da reforma dos espaços de ingresso e atuação docente importantes mecanismos de enquadramento e controle. Mas foi, principalmente, a atenção aos casos de favorecimento político e de insatisfação com a extensão do período de diplomação que permitiu circunscrever os limites das iniciativas que então propunham a reforma das condições de preparo e atuação docente. De modo que, além das transformações que ocorreram a propósito da criação da Escola de Professores e da transformação da Escola Normal do Distrito Federal em Instituto de Educação, também a permanência de práticas em razão das quais a própria reforma é realizada, a conservação de preconceitos sociais e o descontentamento de discentes e suas famílias mantém presença nos mais expressivos episódios da profissionalização do magistério no país. 


\section{REFERÊNCIAS}

ABDALA, Rachel Duarte. A fotografia além da ilustração: Malta e Nicolas construindo imagens da reforma educacional no Distrito Federal (1927-1930). 2003. 203 f. Dissertação (Mestrado em Educação) - Faculdade de Educação, Universidade de São Paulo/ USP, São Paulo, 2003.

ACCÁCIO, Liéte de Oliveira. Instituto de Educação do Rio de Janeiro: a História da formação do professor primário (1927-1937). 1993. $331 \mathrm{f}$.

Dissertação (Mestrado em Educação) - Faculdade de Educação, Universidade Federal do Rio de Janeiro / UFRJ, Rio de Janeiro, 1993.

AMADO, Genolino. O Reino Perdido. Rio de Janeiro: José Olympio, 1971.

ARROYO, Miguel. Mestre, educador, trabalhador (organização do trabalho e profissionalização). 1985. $218 \mathrm{f}$. Tese (Professor Titular) Faculdade de Educação, Universidade Federal de Minas Gerais/UFMG, Belo Horizonte, 1985 .

AZEVEDO, Fernando de. A formação do professorado e a reforma. Boletim de Educação Pública. Ano I, n. 4, p. 479-498, out./dez. 1930.

AZEVEDO, Fernando de. A reforma do ensino no Districto Federal. Discursos e Entrevistas. São Paulo: Cia Melhoramentos, 1929.

BARRETO, Anna Olga Lessa de Barros. Contribuição para a história da escola pública primária do Distrito Federal, no período do Estado Novo (1937-1945). 1985. 143 f. Dissertação (Mestrado em Educação) Pontifícia Universidade Católica do Rio de Janeiro/PUCRJ, Rio de Janeiro, 1985 .

BORGES, Angélica. A urdidura do magistério primário na Corte Imperial: um professor na trama de relações e agências. 2014. 415 f. Tese (Doutorado em Educação) - Faculdade de Educação da USP/Feusp, São Paulo, 2014.

BRITO, Mário de. A admissão à escola secundária. Arquivos do Instituto de Educação. Ano I, n. 1, p. 27-33, jun. 1934.

CARVALHO, Marta. Molde nacional e fôrma cívica: higiene, moral e trabalho no projeto da Associação Brasileira de Educação (1924-1931). Bragança Paulista: Edusf, 1998.

CATANI, Denice. Estudos de história da profissão docente. In: LOPES, Eliane 
Marta; FARIA FILHO, Luciano Mendes; VEIGA, Cynthia Greive. 500 anos de educação no Brasil. Belo Horizonte: Autêntica, 2000, p. 585-599.

DÁVILA, Jerry. Diploma de brancura. São Paulo: Editora Unesp, 2006.

DICIO: Dicionário Online de Português. Disponível em: https://www. dicio.com.br. Acesso em Ago. 2018.

DISTRITO FEDERAL. Decreto n. 5.000, de 11 de julho de 1934. Consolida a legislação sobre a escola secundária do Instituto de Educação e dá outras providências. In: PAGANI, Ivo; VELLOSO, Guilherme Paranhos; DIAS, Alexandre. Coleção de Leis Municipais Vigentes - 1932 a 1935. $5^{\circ}$ volume. Rio de Janeiro: Oficinas Gráficas do Jornal do Brasil, 1937, p. 475-500.

DISTRITO FEDERAL. Decreto n. 4.387, de 8 de setembro de 1933. Consolida a organização técnica e administrativa do aparelho de direção do sistema educacional, instituindo o Departamento de Educação do Distrito Federal. In: PAGANI, Ivo; VELLOSO, Guilherme Paranhos; DIAS, Alexandre. Coleção de Leis Municipais Vigentes - 1932 a 1935. $5^{\circ}$ volume. Rio de Janeiro: Oficinas Gráficas do Jornal do Brasil, 1937, p. 427-436.

DISTRITO FEDERAL. Decreto n. 3.763, de $1^{\circ}$ de fevereiro de 1932a. Modifica algumas disposições do Decreto $\mathrm{n}^{\circ}$ 3.281, de 23 de janeiro de 1928. In: PAGANI, Ivo; VELLOSO, Guilherme Paranhos; DIAS, Alexandre. Coleção de Leis Municipais Vigentes - 1932 a 1935. $5^{\circ}$ volume. Rio de Janeiro: Oficinas Gráficas do Jornal do Brasil, 1937, p. 379.

DISTRITO FEDERAL. Decreto n. 4.o88, de 10 de dezembro de 1932b. Institui uma só categoria de professores primários e fixa seus vencimentos. In: PAGANI, Ivo; VELLOSO, Guilherme Paranhos; DIAS, Alexandre. Coleção de Leis Municipais Vigentes - 1932 a 1935. $5^{\circ}$ volume. Rio de Janeiro: Oficinas Gráficas do Jornal do Brasil, 1937, p. 414-416.

DISTRITO FEDERAL. Decreto n. 3.810, de 19 de março de 1932c. Regula a formação técnica de professores primários, secundários e especializados para o Distrito Federal, com a prévia exigência do curso secundário e transforma em Instituto de Educação a antiga Escola Normal e estabelecimentos anexos. In: PAGANI, Ivo; VELLOSO, Guilherme Paranhos; DIAS, Alexandre. Coleção de Leis Municipais Vigentes - 1932 a 1935. $5^{\circ}$ volume. Rio de Janeiro: Oficinas Gráficas do Jornal do Brasil, 1937, p. 364-378.

FREITAS, Itamar. O estilo pedagógico de Genolino Amado. In: FREITAS, Itamar. Histórias do ensino de história no Brasil (1890-1945). Aracaju: Editoras UFS, 2006. p. 248-258. 
GANDINI, Raquel Pereira Chainho. Tecnocracia, capitalismo e educação em Anísio Teixeira (1930-1935). Rio de Janeiro: Civilização Brasileira, 1980. (Educação e transformação, 04).

KREUTZ, Lucio. Magistério e imigração alemã: o professor paroquial teuto-brasileiro do Rio Grande do Sul no movimento de restauração. 1985. 291 f. Tese (Doutorado em Educação) - Pontifícia Universidade Católica de São Paulo/PUC-SP, São Paulo, 1985.

LEMME, Paschoal. Memórias. 4 v. São Paulo: Cortez; Brasília: Inep, 1988.

LEMOS, Daniel. Professores em movimento: a emergência do associativismo docente na Corte Imperial. 2011. 219 f. Tese (Doutorado em Educação) - Universidade Federal de Minas Gerais/UFMG, Belo Horizonte, 2011.

LOPES, Sonia de Castro. Oficina de Mestres: história, memória e silêncio sobre a Escola de Professores do Instituto de Educação do Rio de janeiro (19321939). Rio de Janeiro: DP\&A; Faperj, 2006.

LOURENÇO FILHO, Manuel Bergstrom. A escola de professores do Instituto de Educação. Arquivos do Instituto de Educação. Ano I, n. 1, p. 15-26, jun. 1934 .

MENDONÇA, Ana Waleska; CARDOSO, Tereza Fachada Levy. A gênese de uma profissão fragmentada. Revista Brasileira de História da Educação, v. 15, p. 31-52, 2002.

MENDONÇA, Ana Waleska; XAVIER, Libania (org.). Por uma política nacional de formação do magistério nacional: o INEP-MEC dos anos 1950-1960. Brasília: Inep, 2008.

NADAI, Elza. A educação como apostolado: história e reminiscências (São Paulo 1930-1970). 1991. 450 f. Tese (Livre-Docência) - Faculdade de Educação da USP/Feusp, São Paulo, 1991.

NAGLE, Jorge. Educação e sociedade na Primeira República. São Paulo: EPU; Edusp, 1974.

NÓVOA, António (org.). Os professores e a sua formação. Lisboa: Dom Quixote, 1991.

NÓVOA, António (org.). Vidas de professores. Porto: Porto Editora, 1992.

NÓVOA, António. Do mestre-escola ao professor do ensino primário. Lisboa: Isef, 1986. 
NUNES, Clarice. Anísio Teixeira: a poesia da ação. Bragança Paulista: Edusf, 2000.

PAULILO, André Luiz. Um capítulo da história da formação e da profissão docente no Brasil: o Instituto de Educação do Distrito Federal e a sua historiografia. Educação e Sociedade, v. 38, n. 138, p. 117-132, jan./mar. 2017.

PINTO, Inára de Almeida Garcia. Um professor em dois mundos: a viagem do professor Luiz Augusto dos Reis à Europa (1891). 2011. 258 f. Tese (Doutorado em Educação) - Faculdade de Educação da USP/Feusp, São Paulo, 2011.

SÁ, Carlos. Quais devem ser os requisitos à admissão às escolas normais. Boletim de Educação Pública. Ano III, n. 5-6, p. 33-40, jan./jun. 1933.

SCHAFFEL, Sarita Léa. O Instituto de Educação do Rio de Janeiro e a constituição de uma identidade profissional (1930-1960). 1999. 249 f. Tese (Doutorado em Educação) - Pontifícia Universidade Católica do Rio de Janeiro/PUCRJ, Rio de Janeiro, 1999.

SCHUELLER, Alessandra Frota Martinez. Culturas escolares e experiências docentes na cidade do Rio de Janeiro. 2002. 200 f. Tese (Doutorado em Educação) - Universidade Federal Fluminense/UFF, Niterói, 2002.

TEIXEIRA, Anísio. Educação pública: administração e desenvolvimento. Relatório do Director Geral do Departamento de Educação do Districto Federal - dezembro de 1934. Rio de Janeiro: Oficina Gráfica do Departamento de Educação, 1935 .

VICENTINI, Paula Perin; LUGLI, Rosário Genta. História da profissão docente no Brasil: representações em disputa. São Paulo: Cortez, 2009.

VIDAL, Diana. Desembaraçando algumas falas: aspectos das reformas Fernando de Azevedo e Anísio Teixeira no Distrito Federal (1927-1935).

Cadernos de História e Filosofia da Educação, v. II, n. 4, p. 75-98, 1998.

VIDAL, Diana. O exercício disciplinado do olhar: livros, leituras e práticas de formação docente no Instituto de Educação do Distrito Federal (1932-1937). Bragança Paulista: Edusf, 2001. (Coleção Historiografia).

XAVIER, Libânia Nacif. Associativismo docente e construção

democrática. Brasil-Portugal: 1950-1980. Rio de Janeiro: EdUerj, 2013. 
ANDRÉ LUIZ PAULILO é professor no Departamento de Filosofia e História da Educação da Faculdade de Educação da Universidade Estadual de Campinas (UNICAMP) onde também atua no Programa de Pós-Graduação em Educação. Graduado em História pela Faculdade de Filosofia, Letras e Ciências Humanas da Universidade de São Paulo (USP), possui mestrado e doutorado em Educação pela Faculdade de Educação da USP.

E-mail: paulilo@unicamp.br

http://orcid.org/0000-0001-8112-8070

Recebido em: 11 de outubro de 2018

Aprovado em: 12 de janeiro de 2020

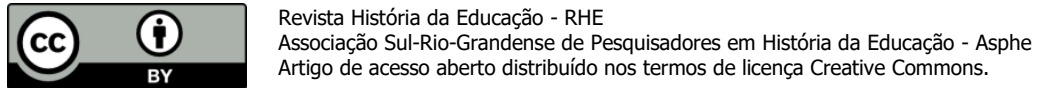

